\title{
ON THE FOUNDATIONS OF MATHEMATICS.
}

PRESIDENTIAL ADDRESS DELIVERED BEFORE THE AMERICAN MATHEMATICAL SOCIETY AT ITS NINTH ANNUAL MEETING, DECEMBER 29, 1902.

BY PRESIDENT ELIAKIM HASTINGS MOORE.

The American Mathematical Society gives its retiring President the privilege of speaking on whatever he may have at heart. Accordingly, this afternoon I propose to consider with you some matters of importance - indeed, perhaps of fundamental importance - in the development of mathematics in this country, and it will duly appear in what non-technical sense I am speaking "On the foundations of mathematics."

\section{A VIEW.}

\section{Abstract Mathematics.}

The notion within a given domain of defining the objects of consideration rather by a body of properties than by particular expressions or intuitions is as old as mathematics itself. And yet the central importance of the notion appeared only during the last century - in a host of researches on special theories and on the foundations of geometry and analysis. Thus has arisen the general point of view of what may be called abstract mathematics. One comes in touch with the literature very conveniently by the mediation of Peano's Revue des Mathématiques. The Italian school of Peano and the Formulaire Mathematique, published in connection with the Revue, are devoted to the codification in Peano's symbolic language of the principal mathematical theories, and to researches on abstract mathematics. General interest in abstract mathematics was aroused by Hilbert's Gauss-Weber Festschrift, of 1899 : "Ueber die Grundlagen der Geometrie," a memoir rich in results and suggestive in methods; I refer to the reviews by Sommer,* Poincaré, $\uparrow$ Halsted, + Hedrick, $\S$ Veblen. $\|$

* Bulletin, vol. 6 (1900), p. 287.

† Bull. des Sciences Mathém., vol. 26 (1902), p. 249.

\$ The Open Court, September, 1902.

3. Bulletrin, vol. 9 (1902), p. 158.

|| The Monist, January, 1903. 
We have as a basal science logic, and as depending upon it the special deductive sciences which involve undefined symbols and whose propositions are not all capable of proof. The symbols denote either classes of elements or relations amongst elements. In any such science one may choose in various ways the system of undefined symbols and the system of undemonstrated or primitive propositions, or postulates. Every proposition follows from the postulates by a finite number of logical steps. A careful statement of the fundamental generalities is given by Padoa in a paper* before the Paris Congress of Philosophy, 1900.

Having in mind a definite system of undefined symbols and a definite system of postulates, we have first of all the notion of the compatibility of these postulates; that is, that it is impossible to prove by a finite number of logical steps the simultaneous validity of a statement and its contradictory statement. In the next place, the question of the independence of the postulates or the irreducibility of the system of the postulates ; that is, that no postulate is provable from the remaining postulates. Padoa introduces the notion of the irreducibility of the system of undefined symbols. A system of undefined symbols is said to be reducible if for one of the symbols $X$ it is possible to establish as a logical consequence of the assumption of the validity of the postulates a nominal or symbolic definition of the form $X=A$, where in the expression $A$ there enter only the undefined symbols distinct from $X$. For the purpose of practical application, it seems to be desirable to modify the definition so as to call the system of undefined symbols reducible if there is a nominal definition $X=A$ of one of them $X$ in terms of the others such that in any interpretation of the science the postulates retain their validity when instead of the initial interpretation of the symbol $X$ there is placed the interpretation $A$ of that symbol. If the system of symbols is reducible in the sense of the original definition it is in the sense of the new definition, but not necessarily conversely, as appears for instance from the following example, occurring in the foundations of geometry.

Hilbert uses the following undefined symbols: "point," " line," " plane," "incidence" of point and line, " incidence"

* “Essai d'une théorie algébrique des nombres entiers, précédé d'une Introduction logique à une théorie déductive quelconque." Bibliothèque du Congrès International de Philosophie, vol. 3, p. 309. 
of point and plane, "between," and " congruent." Now it is possible to give for the symbol "plane" a symbolic definition in terms of the other undefined symbols - for instance, a plane is a certain class of points (as Peano showed in 1892), or again, a plane is a certain class of lines ; while the notion "incidence" of point and plane receives convenient definition. It is apparent from the fact that these definitions may be given in these two ways that Hilbert's system of undefined symbols is not in Padoa's sense irreducible - at least, in so far as the symbols "plane," "incidence" of point and plane are concerned - while it is equally clear that these symbols are in the abstract geometry superfluous.

In his dissertation on euclidean geometry, Mr. Veblen, following the example of Pasch and Peano, takes as undefined symbols "point" and "between," or "point" and "segment." In terms of these two symbols alone he expresses a set of independent fundamental postulates of euclidean geometry, in the first place developing the projective geometry, and then as to congruence relating himself to the point of view of Klein in his "Erlangen Programm," whereby the group of movements of euclidean geometry enters as a certain subgroup of the group of collineations of projective geometry. Here arises an interesting question as to the sense in which the undefined symbol "congruence" is superfluous in the euclidean geometry based upon the symbols " point," "between." One sees at once that a definition of "congruence" involves parametric points in its expression, while on the other hand a definition of the system of all "planes," that is, of the general concept "plane," involves no such parametric elements. But, again, just as there exist distinct definitions of " congruence," owing to a variation of the parametric points, so there exist distinct definitions of the general concept "plane," as was indicated a moment ago. One has the feeling that the state of affairs must be as follows: In any interpretation of - say - Hilbert's symbols, wherein the postulates of Hilbert are valid, every valid statement which does not involve the symbol "plane" in direct connection with the general logical symbol ( =) of symbolic definition, remains valid when we modify it in accordance with either of the definitions of "plane" previously referred to. On the other hand, this state of affairs does not hold for the symbol "congruence." The proof of the former statement would seem to involve fundamental logical niceties. 
The compatibility and the independence of the postulates of a system of postulates of a special deductive science have been up to this time always made to depend upon the self-consistency of some other deductive science; for instance, geometry depends thus upon analysis, or analysis upon geometry. The fundamental and still unsolved problem in this direction is that of the direct proof of the compatibility of the postulates of arithmetic, or of the real number system of analysis. (To the Society this morning Dr. Huntington exhibited two sets of independent postulates for this real number system.) This is the second of the twenty-three problems listed by Hilbert in his address before the Paris Mathematical Congress of 1900.

The Italian writers on abstract mathematics for the most part make use of Peano's symbolism. One may be tempted to feel that this symbolism is not an essential part of their work. It is only right to state, however, that the symbolism is not difficult to learn, and there is testimony to the effect that the symbolism is actually of great value to the investigator in removing from attention the concrete connotations of the ordinary terms of general and mathematical language. But of course the essential difficulties are not to be obviated by the use of any symbolism however delicate.

Indeed the question arises whether the abstract mathematicians in making precise the metes and bounds of logic and the special deductive sciences are not losing sight of the evolutionary character of all life processes, whether in the individual or in the race. Certainly the logicians do not consider their science as something now fixed. All science, logic and mathematics included, is a function of the epoch - all science, in its ideals as well as in its achievements. Thus, with Hilbert, let a special deductive or mathematical science be based upon a finite number of symbols related by a finite number of compatible postulates, every proposition of the science being deducible by a finite number of logical steps from the postulates. The content of this conception is far from absolute. It involves what presuppositions as to general logic? What is a finite number? In what sense is a postulate - for example, that any two distinct points determine a line - a single postulate? What are the permissible logical steps of deduction? Would the usual syllogistic steps of formal logic suffice? Would they suffice even with the aid of the principle of mathematical induc- 
tion, in which Poincaré finds* the essential synthetic element of mathematical argumentation, the basis of that generality without which there would be no science? In what sense is mathematical induction a single logical step of deduction?

One has then the feeling that the carrying out in an absolute sense of the program of the abstract mathematicians will be found impossible. At the same time, one recognizes the importance attaching to the effort to do precisely this thing. The requirement of rigor tends toward essential simplicity of procedure, as Hilbert has insisted in his Paris address, and the remark applies likewise to this question of mathematical logic and its abstract expression.

\section{Pure and Applied Mathematics.}

In the ultimate analysis for any epoch, we have general logic, the mathematical sciences, $\uparrow$ that is, all special formally and abstractly deductive self-consistent sciences, and the natural sciences, which are inductive and informally deductive. While this classification may be satisfactory as an ideal one, it fails to recognize the fact that in mathematical research one by no means confines himself to processes which are mathematical according to this definition; and if this is true with respect to the research of professional mathematicians, how much more is it true with respect to the study, which should throughout be conducted in the spirit of research, on the part of students of mathematics in the elementary schools and colleges and universities. I refer to the articles \$ of Poincaré on the rôle of intuition and logic in mathematical research and education.

It is apparent that this ideal classification can be made by the devotee of science only when he has reached a considerable degree of scientific maturity, that perhaps it would fail to appeal to non-mathematical experts, and that it does not accord with the definitions given by practical working mathematicians. Indeed the attitude of practical mathematicians toward this

* "Sur la nature du raisonnement mathématique." Revue de Métaphysique et de Morale, vol. 2 (1894), pp. 371-384.

+ Of which none is at present known to exist.

‡ "La logique et l'intuition dans la science mathématique et dans l'enseignement ;" L'Enseignement Mathématique, vol. 1 (1899), pp. 157-162.

"Du rôle de l'intuition et de la logique en Mathématiques"; Compte Rendu du Deuxième Congrès International des Mathématiciens. (Paris [1900], 1902), pp. 115-130.

"Sur les rapports de l' Analyse pure et de la Physique mathématique" ; Conference, Zurich, 1897 ; Acta Mathematica, vol. 21, p. 238. 
whole subject of abstract mathematics, and especially the symbolic form of abstract mathematics, is not unlike that of the physicist toward the whole subject of theoretical mathematics, and in turn not unlike that of the engineer toward the whole subject of theoretical physics and mathematics. Furthermore, everyone understands that many of the most important advances of pure mathematics have arisen in connection with investigations originating in the domain of natural phenomena.

Practically then it would seem desirable for the interests of science in general that there should be a strong body of men thoroughly possessed of the scientific method in both its inductive and its deductive forms. We are confronted with the questions: What is science? What is the scientific method? What are the relations between the mathematical and the natural scientific processes of thought? As to these questions I refer to articles and addresses of Poincaré,* Boltzmann $\dagger$ and Burkhardt, $\$$ and to Mach's Science of Mechanics and Pearson's Grammar of Science.

Without elaboration of metaphysical or psychological details, it is sufficient to refer to the thought that the individual as confronted with the world of phenomena in his effort to obtain control over this world is gradually forced to appreciate a knowledge of the usual co-existences and sequences of phenomena, and that science arises as the body of formulas serving to epitomize or summarize conveniently these usual coexistences and sequences. These formulas are of the nature of more or less exact descriptions of phenomena; they are not of the nature of explanations. Of all the relations entering into the formulas of science, the fundamental mathematical notions of number and measure and form were among the earliest, and pure mathematics in its ordinary acceptation may be understood to be the systematic development of the properties of these notions, in accordance with conditions prescribed by physical phenomena. Arithmetic and geometry, closely united in mensuration and trigonometry, early reached a high degree of ad-

* In addition to those already cited : "On the Foundations of Geometry" ; The Monist, vol. 9, October, 1898, pp. 1-43. "Sur les principes de la Mécanique;" Bibliothèque du Congrès International de Philosophie, vol. 3 , pp. 457-494.

† "Ueber die Methoden der theoretischen Physik" ; Dyck's Katalog mathematischer und mathematisch-physikalischer Modelle, Apparate und Instrumente, pp. 89-98 (Munich, 1892).

$\ddagger$ "Mathematisches und naturwissenschaftliches Denken" ; Jahresber. der Deutschen Math.-Ver., vol. 11 (1902), pp. 49-57. 
vancement. But after the development of the generalizing literal notations of algebra, and largely in response to the insistent demands of mechanics, astronomy and physics, the seventeenth century, binding together arithmetic and geometry infinitely more closely, created analytic geometry and the infinitesimal calculus, those mighty methods of research whose application to all branches of the theoretical and practical physical sciences so fundamentally characterizes the civilization of to-day.

The eighteenth century was devoted to the development of the powers of these new instruments in all directions. While this development continued during the nineteenth century, the dominant note of the nineteenth century was that of critical reorganization of the foundations of pure mathemathics, so far, for instance, the majestic edifice of analysis was seen to rest upon the arithmetic of positive integers alone. This reorganization and the consequent course of development of pure mathematics were independent of the question of the application of mathematics to the sister sciences. There has thus arisen a chasm between pure mathematics and applied mathematics. There have not been lacking, however, influences making toward the bridging of this chasm; one thinks especially of the whole influence of Klein in Germany and of the Ecole Polytechnique in France. As a basis of union of the pure mathematicians and the applied mathematicians Klein has throughout emphasized the importance of a clear understanding of the relations between those two parts of mathematics which are conveniently called "mathematics of precision" and " mathematics of approximation," and I refer especially to his latest work of this character, Anwendung der Differential- und Integralrechnung auf Geometrie : Eine Revision der Principien (Göttingen, Summer Semester, 1901; Teubner, 1902). This course of lectures is designed to present particular applications of the general notions of Klein, and furthermore it is in continuation of the discussion between Pringsheim and Klein and others, as to the desirable character of lectures on mathematics in the universities of Germany.

\section{Elementary Mathematics.}

This separation between pure mathematics and applied mathematics is grievous even in the domain of elementary mathe- 
matics. In witness, in the first place: The workers in physics, chemistry and engineering need more practical mathematics, and numerous text-books, in particular, on calculus, have recently been written from the point of view of these allied subjects. I refer to the works by Nernst and Schoenflies, ${ }^{*}$ Lorentz, $\dagger$ Perry $\ddagger$ and Mellor, $\S$ and to a book on the very elements of mathematics now in preparation by Oliver Lodge.

In the second place, I dare say you are all familiar with the surprisingly vigorous and effective agitation with respect to the teaching of elementary mathematics which is at present in progress in England, largely under the direction of John Perry, Professor of Mechanics and Mathematics of the Royal College of Science, London, and chairman of the Board of Examiners of the Board of Education in the subjects of engineering, including practical plane and solid geometry, applied mechanics, practical mathematics, in addition to more technical subjects, and in this capacity in charge of the education of some hundred thousand apprentices in English night schools. The section on Education of the British Association had its first session at the Glasgow meeting, 1901, and the session was devoted to the consideration, in connection with the section on Mathematics and Physics, of the question of the pedagogy of mathematics, and Perry opened the discussion by a paper on "The Teaching of Mathematics." A strong committee under the chairmanship of Professor Forsyth, of Cambridge, was appointed " to report upon improvements that might be effected in the teaching of mathematics, in the first instance, in the teaching of elementary mathematics, and upon such means as they think likely to effect such improvements." The paper of Perry, with the discussion of the subject at Glasgow and additions including the report of the committee as presented to the British Association at its Belfast meeting, September, 1902, are collected in a small

* Nernst und Schoenflies : Einführung in die mathematische Behandlung der Naturwissenschaften (Munich and Leipsic, 1895), the basis of Young and Linebarger's Elements of Differential and Integral Calculus (New York, 1900). $1900)$

†Lorentz: Lehrbuch der Differential- und Integralrechnung (Leipsic,

†Perry : Calculus for Engineers. (Second edition, London, E. Arnold, 1897); German translation by Fricke (Teubner, 1902). Cf. also the citations given later on.

3. Mellor: Higher Mathematics for Students of Chemistry and Physics, with special reference to Practical Work. (Longmans, Green \& Co., 1902. Pp. xxi +543 .) 
volume, "Discussion on the Teaching of Mathematics," edited by Professor Perry (Macmillan ; second edition, 1902).*

One should consult the books of Perry, Practical Mathematics, $\dagger$ Applied Mechanics, $\$$ Calculus for Engineers $\S$ and England's Neglect of Science, $\|$ and his address T on "The Education of Engineers" — and furthermore, the files from 1899 on of the English journals, Nature, School World, Journal of Education and Mathematical Gazette.

One important purpose of the English agitation is to relieve the English secondary school teachers from the burden of a too precise examination system, imposed by the great examining bodies; in particular, to relieve them from the need of retaining Euclid as the sole authority in geometry, at any rate with respect to the sequence of propositions. Similar efforts made in England about thirty years ago were unsuccessful. Apparently the forces operating since that time have just now broken forth into successful activity ; for the report of the British Association committee was distinctly favorable, in a conservative sense, to the idea of reform, and already noteworthy initial changes have been made in the regulations for the secondary examinations by the examination syndicates of the universities of Oxford, Cambridge and London.

The reader will find the literature of this English movement very interesting and suggestive. For instance, in a letter to Nature (volume 65, page 484 ; March 27, 1902), Perry mildly apologizes for having to do with the movement whose immediate results are likely to be merely slight reforms, instead of the thoroughgoing reforms called for in his pronouncements and justified by his marked success during over twenty years as a teacher of practical mathematics. He asserts that the orthodox logical sequence in mathematics is not the only possible one; that on the contrary a more logical sequence than the orthodox one (because one more possible of comprehension by the students) is based upon the notions underlying the infinitesimal

* Cf. also "Report on the Teaching of Elementary Mathematics, issued by the Mathematical Association" (G. Bell \& Sons, London, 1902).

+ Published for the Board of Education by Eyre and Spottiswoode (London, 1899).

D. Van Nostrand Co., New York, 1898.

\& Second edition, London, E. Arnold, 1897.

ii T. Fisher Unwin, London, 1900.

I In opening the discussion of the sections on Engineering and on Education at the Belfast, 1902, meeting of the British Association. Published in Science, Nov. 14, 1902. 
calculus taken as axioms; for instance, that a map may be drawn to scale; the notions underlying the many uses of squared paper; that decimals may be dealt with as ordinary numbers. He asserts as essential that the boy should be familiar (by way of experiment, illustration, measurement, and by every possible means) with the ideas to which he applies his logic ; and moreover that he should be thoroughly interested in the subject studied; and he closes with this peroration :

\section{" "Great God! I'd rather be \\ A pagan, suckled in a creed outworn.'}

I would rather be utterly ignorant of all the wonderful literature and science of the last twenty-four centuries, even of the wonderful achievements of the last fifty years, than not to have the sense that our whole system of so-called education is as degrading to literature and philosophy as it is to English boys and men."

As a pure mathematician, I hold as the most important suggestion of the English movement the suggestion of Perry's, just cited, that by emphasizing steadily the practical sides of mathematics, that is, arithmetic computations, mechanical drawing and graphical methods generally, in continuous relation with problems of physics and chemistry and engineering, it would be possible to give very young students a great body of the essential notions of trigonometry, analytic geometry, and the calculus. This is accomplished on the one hand by the increase of attention and comprehension obtained by connecting the abstract mathematics with subjects which are naturally of interest to the boy, so that, for instance, all the results obtained by theoretic process are capable of check by laboratory process, and on the other hand by a diminution of emphasis on the systematic and formal sides of the instruction in mathematics. Undoubtedly many mathematicians will feel that this decrease of emphasis will result in much if not irreparable injury to the interests of mathematics. But $I$ am inclined to think that the mathematician with the catholic attitude of an adherent of science in general (and at any rate with respect to the problems of the pedagogy of elementary mathematics there is no other rational attitude) will see that the boy will be learning to make practical use in his scientific investigations, to be sure in a naïve and elementary way, of the finest mathematical tools which the centuries have forged, that under 
skillful guidance he will learn to be interested not merely in the achievements of the tools but in the theory of the tools themselves, and that thus he will ultimately have a feeling towards his mathematics extremely different from that which is now met with only too frequently - a feeling that mathematics is indeed itself a fundamental reality of the domain of thought, and not merely a matter of symbols and arbitrary rules and conventions.

\section{The American Mathematical Society.}

The American Mathematical Society has, naturally, interested itself chiefly in promoting the interests of research in mathematics. It has, however, recognized that those interests are closely bound up with the interests of education in mathematics. I refer in particular to the valuable work done by the committee appointed, with the authorization of the Council, by the Chicago Section of the Society, to represent mathematics in connection with Dr. Nightingale's committee of 1899 of the National Educational Association in the formulation of standard curricula for high schools and academies, and to the fact that two committees are now at work, one appointed in December, 1901, by the Chicago Section, to formulate the desirable conditions for the granting by institutions of the Mississippi Valley, of the degree of Master of Arts for work in mathematics, and the other appointed by the Society at its last summer meeting to coöperate with similar committees of the National Educational Association and of the Society for the Promotion of Engineering Education, in formulating standard definitions of requirements in mathematical subjects for admission to colleges and technological schools ; and furthermore I refer to the fact that (although not formally) the Society has made a valuable contribution to the interests of secondary education in that the College Entrance Examination Board has as its Secretary the principal founder of the Society. I have accordingly felt at liberty to bring to the attention of the Society these matters of the pedagogy of elementary mathematics, and I do so with the firm conviction that it would be possible for the Society, by giving still more attention to these matters, to further most effectively the highest interests of mathematics in this country. 


\section{A Vision. \\ An Invitation.}

The pure mathematicians are invited to determine how mathematics is regarded by the world at large, including their colleagues of other science departments and the students of elementary mathematics, and to ask themselves whether by modification of method and attitude they may not win for it the very high position in general esteem and appreciative interest which it assuredly deserves.

This general invitation and the preceding summary view invoke this vision of the future of elementary mathematics in this country.

\section{The Pedagogy of Elementary Mathematics.}

We survey the pedagogy of elementary mathematics in the primary schools, in the secondary schools, and in the junior colleges (the lower collegiate years). It is, however, understood that there is a movement for the enlargement of the strong secondary schools, by the addition of the two years of junior college work and by the absorption of the last two or three grades of the primary schools, into institutions more of the type of the German gymnasia and the French lycée;* in favor of this movement there are strong arguments, and among them this, that in such institutions, especially if closely related to strong colleges or universities, the mathematical reforms may the more easily be carried out.

The fundamental problem is that of the unification of pure and applied mathematics. If we recognize the branching implied by the very terms "pure," "applied," we have to do with a special case of the correlation of different subjects of the curriculum, a central problem in the domain of pedagogy from the time of Herbart on. In this case, however, the fundamental solution is to be found rather by way of indirection-by arranging the curriculum so that throughout the domain of elementary mathematics the branching be not recognized.

\section{The Primary Schools.}

Would it not be possible for the children in the grades to be trained in power of observation and experiment and reflection

\footnotetext{
* As to the mathematics of these institutions, one may consult the book on "The Teaching of Mathematics in the Higher Schools of Prussia" (New York: Longmans Green \& Co., 1900) by Professor Young, and the article (Bulletin, vol. 6, p. 225) by Professor Pierpont. *
} 
and deduction so that always their mathematics should be directly connected with matters of thoroughly concrete character? The response is immediate that this is being done today in the kindergartens and in the better elementary schools. I understand that serious difficulties arise with children of from nine to twelve years of age, who are no longer contented with the simple concrete methods of earlier years and who nevertheless are unable to appreciate the more abstract methods of the later years. These difficulties, some say, are to be met by allowing the mathematics to enter only implicitly in connection with the other subjects of the curriculum. But rather the material and methods of the mathematics should be enriched and vitalized. In particular, the grade teachers must make wiser use of the foundations furnished by the kindergarten. The drawing and the paper folding must lead on directly to systematic study of intuitional geometry, including the construction of models and the elements of mechanical drawing, with simple exercises in geometrical reasoning.* The geometry must be closely connected with the numerical and literal arithmetic. The cross-grooved tables of the kindergarten furnish an especially important type of connection, viz., a conventional graphical depiction of any phenomenon in which one magnitude depends upon another. These tables and the similar cross-section blackboards and paper must enter largely into all the mathematics of the grades. The children are to be taught to represent, according to the usual conventions, various familiar and interesting phenomena and to study the properties of the phenomena in the pictures; to know, for example, what concrete meaning attaches to the fact that a graph curve at a certain point is going down or is going up or is horizontal. Thus the problems of percentage, interest, etc., have their depiction in straight line or broken line graphs.

\section{The Secondary Schools.}

Pending the reform of the primary schools, the secondary schools must advance independently. In these schools at present, according to one type of arrangement, we find algebra in the first year, plane geometry in the second, physics

\footnotetext{
* Here I refer to the very suggestive paper of Benchara Branford, entitled "Measurement and Simple Surveying. An Experiment in the Teaching of Elementary Geometry" to a small class of beginners of about ten years of age (Journal of Education, London, the first part appearing in the number for August, 1899).
} 
in the third, and the more difficult parts of algebra and solid geometry, with review of all the mathematics, in the fourth.

Engineers* tell us that in the schools algebra is taught in one water-tight compartment, geometry in another and physics in another, and that the student learns to appreciate (if ever) only very late the absolutely close connection between these different subjects, and then, if he credits the fraternity of teachers with knowing the closeness of this relation, he blames them most heartily for their unaccountably stupid way of teaching him. If we contrast this state of affairs with the state of affairs in the solid four years' course in Latin, I think we are forced to the conclusion that the organization of instruction in Latin is much more perfect than that of the instruction in mathematics.

The following question arises: Would it not be possible to organize the algebra, geometry, and physics of the secondary school into a thoroughly coherent four years' course, comparable in strength and closeness of structure with the four years' course in Latin? (Here under physics I conclude astronomy and the more mathematical and physical parts of physiography.) It would seem desirable that just as the systematic development of theoretical mathematics is deferred to a later period, likewise much of theoretical physics might well be deferred. Let the physics also be made thoroughly practical. At any rate so far as the instruction of boys is concerned, the course should certainly have its character largely determined by the conditions which would be imposed by engineers. What kind of two or three years' course in mathematics and physics would a thoroughly trained engineer give to boys in the secondary school? Let this body of material postulated by the engineer

* Why is it that one of the sanest and best-informed scientific men living, a man not himself an engineer, can charge mathematicians with killing off every engineering school on which they can lay hands? Why do engineers so strongly urge that the mathematical courses in engineering schools be given by practical engineers?

And why can a reviewer of "Some Recent Books on Mechanics" write with truth : "The student's previous training in algebra, geometry, trigonometry, analytic geometry, and calculus as it is generally taught has been necessarily quite formal. These mighty algorithms of formal mathematics must be learned so that they can be applied with readiness and precision. But with mechanics comes the application of these algorithms, and formal, do-by-rote methods, though often possible, yield no results of permanent value. How to elicit and cultivate thought is now of primary importance"? (E. B. Wilson, Bulletis, Oct., 1902). But is it conceivable that in any part of the education of the student the problem of eliciting and cultivating thought should not be of primary importance? 
serve as the basis of the four years' course. Let the instruction in the course, however, be given by men who have received expert training in mathematics and physics as well as in engineering, and let the instruction be so organized that with the development of the boy in appreciation of the practical relations shall come simultaneously his development in the direction of theoretical physics and theoretical mathematics.

Perry is quite right in insisting that it is scientifically legitimate in the pedagogy of elementary mathematics to take a large body of basal principles instead of a small body, and to build the edifice upon the larger body for the earlier years, reserving for the later years the philosophic criticism of the basis itself and the reduction of the basal system.

To consider the subject of geometry in all briefness: With the understanding that proper emphasis is laid upon all the concrete sides of the subject, and that furthermore from the beginning exercises in informal deduction * are introduced increasingly frequently, when it comes to the beginning of the more formal deductive geometry why should not the students be directed each for himself to set forth a body of geometric fundamental principles, on which he would proceed to erect his geometric edifice? This method would be thoroughly practical and at the same time thoroughly scientific. The various students would have different systems of axioms, and the discussions thus arising naturally would make clearer in the minds of all precisely what are the functions of the axioms in the theory of geometry. The students would omit very many of the axioms, which to them would go without saying. The teacher would do well not to undertake to make the system of axioms thoroughly complete in the abstract sense. "Sufficient unto the day is the precision thereof." The student would very probably wish to take for granted all the ordinary properties of measurement and of motion, and would be ready at once to accept the geometrical implications of coördinate geometry. He could then be brought with extreme ease to the consideration of fundamental notions of the calculus as treated concretely and he would find those notions delightfully real

* In an article shortly to appear in the Educational Review on "The Psychological and the Logical in the Teaching of Geometry," Professor John Dewey, calling attention to the evolutionary character of the education of an individual, insists that there should be no abrupt transition from the introductory, intuitional geometry to the systematic, demonstrative geometry. 
and powerful, whether in the domain of mathematics or of physics or of chemistry.

To be sure, as Study has well insisted, for a thorough comprehension of even the elementary parts of euclidean geometry the non-euclidean geometries are absolutely essential. But the teacher is teaching the subject for the benefit of the students, and it must be admitted that beginners in the study of demonstrative geometry cannot appreciate the very delicate considerations involved in the thoroughly abstract science. Indeed, one may conjecture that, had it not been for the brilliant success of Euclid in his effort to organize into a formally deductive system the geometric treasures of his times, the advent of the reign of science in the modern sense might not have been so long deferred. Shall we then hold that in the schools the teaching of demonstrative geometry should be reformed in such a way as to take account of all the wonderful discoveries which have been made - many even recently — in the domain of abstract geometry? And should similar reforms be made in the treatment of arithmetic and algebra? To make reforms of this kind : would it not be to repeat more gloriously the error of those followers of Euclid who fixed his Elements as a textbook for elementary instruction in geometry for over two thousand years? Everyone agrees that professional mathematicians should certainly take account of these great developments in the technical foundations of mathematics, and that ample provision should be made for instruction in these matters ; and on reflection, everyone agrees further that this provision should be reserved for the later collegiate and university years.

\section{The Laboratory Method.}

This program of reform calls for the development of a thoroughgoing laboratory system of instruction in mathematics and physics, a principal purpose being as far as possible to develop on the part of every student the true spirit of research, and an appreciation, practical as well as theoretic, of the fundamental methods of science.

In connection with what has already been said, the general suggestions I now add will, I hope, be found of use when one enters upon the questions of detail involved in the organization of the course.

As the world of phenomena receives attention by the individual, the phenomena are described both graphically and in 
terms of number and measure; the number and measure relations of the phenomena enter fundamentally into the graphical depiction, and furthermore the graphical depiction of the phenomena serves powerfully to illuminate the relations of number and measure. This is the fundamental scientific point of view. Here under the term graphical depiction I include representation by models.

To provide for the needs of laboratory instruction, there should be regularly assigned to the subject two periods, counting as one period in the curriculum.

As to the possibility of effecting this unification of mathematics and physics, in the secondary schools, objection will be made by some teachers that it is impossible to do well more than one thing at a time. This pedagogic principle of concentration is undoubtedly sound. One must, however, learn how to apply it wisely. For instance, in the physical laboratory it is undesirable to introduce experiments which teach the use of the calipers or of the vernier or of the slide rule. Instead of such uninteresting experiments of limited purpose, the students should be directed to extremely interesting problems which involve the use of these instruments and thus be lead to learn to use the instruments as a matter of course and not as a matter of difficulty. Just so the smaller elements of mathematical routine can be made to attach themselves to laboratory problems, arousing and retaining the interest of the students. Again, everything exists in its relations to other things, and in teaching the one thing the teacher must illuminate these relations.

Every result of importance should be obtained by at least two distinct methods, and every result of especial importance by two essentially distinct methods. This is possible in mathematics and the physical sciences, and thus the student is made thoroughly independent of all authority.

All results should be checked, if only qualitatively or "to the first significant figure." In setting problems in practical mathematics (arithmetical computation or geometrical construction) the teacher should indicate the amount or percentage of error permitted in the final result. If this amount or percentage is chosen conveniently in the different examples, the student will be lead to the general notion of closer and closer approximation to a perfectly definite result and thus in a practical way to the fundamental notions of the theory of limits and of ir- 
rational numbers. Thus, for instance, uniformity of convergence can be taught beautifully in connection with the concrete notion of area under a monotonic curve between two ordinates, by a figure due to Newton, while the interest will be still greater if in the diagram area stands for work done by an engine.

The teacher should lead up to an important theorem gradually in such a way that the precise meeting of the statement in question, and further, the practical $-i$. e., computational or graphical or experimental - truth of the theorem is fully appreciated; and furthermore, the importance of the theorem is understood, and indeed the desire for the formal proof of the proposition is awakened, before the formal proof itself is developed. Indeed, in most cases, much of the proof should be secured by the research work of the students themselves.

Some hold that absolutely individual instruction is the ideal, and a laboratory method has sometimes been used for the purpose of attaining this ideal. The laboratory method has as one of its elements of great value the flexibility which permits students to be handled as individuals or in groups. The instructor utilizes all the experience and insight of the whole body of students. He arranges it so that the students consider that they are studying the subject itself, and not the words, either printed or oral, of any authority on the subject. And in this study they should be in the closest coöperation with one another, and with their instructor, who is in a desirable sense one of them and their leader. Instructors may fear that the brighter students will suffer if encouraged to spend time in coöperation with those not so bright. But experience shows that just as every teacher learns by teaching, so even the the brightest students will find themselves much the gainers for this coöperation with their colleagues.

In agreement with Perry, it would seem possible that the student might be brought into vital relation with the fundamental elements of trigonometry, analytic geometry, and the calculus, on condition that the whole treatment in its origin is and in its development remains closely associated with thoroughly concrete phenomena. With the momentum of such practical education in the methods of research in the secondary school, the college students would be ready to proceed rapidly and deeply in any direction in which their personal interests might lead them. In particular, for instance, one might ex- 
pect to find effective interest on the part of college students in the most formal abstract mathematics.

For all students who are intending to take a full secondary school course, in preparation for colleges or technological schools, I am convinced that the laboratory method of instruction in mathematics and physics, which has been briefly suggested, is the best method of instruction, for students in general, and for students expecting to specialize in pure mathematics, in pure physics, in mathematical physics or astronomy, or in any branch of engineering.

\section{Evolution, not Revolution.}

In contemplating this reform of secondary school instruction we must be careful to remember that it is to be accomplished as an evolution from the present system and not as a revolution of that system. Even under the present organization of the curriculum the teachers will find that much improvement can be made by closer coöperation one with another; by the introduction so far as possible of the laboratory two-period plan; and in any event by the introduction of laboratory methods ; laboratory record books, cross section paper, computational and graphical methods in general, including the use of colored inks and chalks; the coöperation of students; and by laying emphasis upon the comprehension of propositions rather than upon the exhibition of comprehension.

\section{The Junior Colleges.}

Just as the secondary schools should begin to reform without waiting for the improvement of the primary schools, so the elementary collegiate courses should be modified at once without waiting for the reform of the secondary schools. And naturally, in the initial period of reform, the education in each higher domain will involve many elements which later on will be transferred to the later domain.

Further, by the introduction into the junior colleges of the laboratory method of instruction it will be possible for the colleges and universities to take up a duty which for the most part has been neglected in this country. For, although we have normal schools and other training schools for those who expect to teach in the grades, little attention has as yet been given to the training of those who will become secondary 
school teachers. 'The better secondary schools to-day are securing the services of college graduates who have devoted special attention to the subjects which they intend to teach, and as time goes on the positions in these schools will as a rule be filled (as in France and Germany) by those who have supplemented their college course by several years of university work. Here these college and university graduates proceed at once to their work in the secondary schools. Now in the laboratory courses of the junior college let those students of the senior colleye and graduate school who are to go into the teaching career be given training in the pedagogy of mathematics according to the laboratory system ; for such a student the laboratory would be a laboratory in the pedagogy of mathematics ; that is, he would be a colleague-assistant of the instructor. By this arrangement, the laboratory instruction of the colleges would be strengthened at the same time that well equipped teachers would be prepared for work in the secondary schools.

\section{The Freedom of the Secondary Schools.}

The secondary schools are everywhere preparing students for colleges and technological schools, and whether the requirements of those institutions are expressed by way of examination of students or by way of the conditions for the accrediting of schools or teachers, the requirements must be met by the secondary schools. The stronger secondary school teachers too often find themselves shackled by the specific requirements imposed by local or by collegiate authorities. Teaching must become more of a profession. And this implies not only that the teacher must be better trained for his career, but that also in his career he be given with greater freedom greater responsibility. To this end closer relations should be established between the teachers of the colleges and those of the secondary schools; standing provision should be made for conferences as to improvement of the secondary school curricula and in the collegiate admission requirements; and the leading secondary school teachers should be steadily encouraged to devise and try out plans looking in any way toward improvement.

Thus the proposed four years' laboratory course in mathematics and physics will come to existence by way of evolution. In a large secondary school, the strongest teachers, finding the 
project desirable and feasible, will establish such a course alongside the present series of disconnected courses - and as time goes on their success will in the first place stimulate their colleagues to radical improvements of method under the present organization and finally to a complete reorganization of the courses in mathematics and physics.

\section{The American Mathematical Society.}

Do you not feel with me that the American MathematiCAL SocIETY, as the organic representative of the highest interests of mathematics in this country, should be directly related with the movement of reform? And, to this end, that the Society, enlarging its membership by the introduction of a large body of the strongest teachers of mathematics in the secondary schools should give continuous attention to the question of improvement of education in mathematics, in institutions of all grades? That there is need for the careful consideration of such questions by the united body of experts, there is no doubt whatever, whether or not the general suggestions which we have been considering this afternoon turn out to be desirable and practicable. In case the question of pedagogy does come to be an active one, the Society might readily hold its meetings in two divisions - a division of research and a division of pedagogy.

Furthermore, there is evident need of a national organization having its center of gravity in the whole body of science instructors in the secondary schools; and those of us interested in these questions will naturally relate ourselves also to this organization. It is possible that the newly-formed Central Association of Physics Teachers may be the nucleus of such an organization.

\section{Conclusion.}

The successful execution of the reforms proposed would seem to be of fundamental importance to the development of mathematics in this country. I urge that individuals and organizations proceed to the consideration of the general question of reform with all the related questions of detail. Undoubtedly in many parts of the country improvements in organization and methods of instruction mathematics have been making these last years. All persons who are, or may become, actively interested in this movement of reform should in some way 
unite themselves in order that the plans and the experience, whether of success or of failure, of one may be immediately made available in the guidance of his colleagues.

I may refer to the centers of activity with which I am acquainted. Miss Edith Long, in charge of the Department of Mathematics in the Lincoln (Neb.) High School, reports upon the experience of several years in the correlation of algebra, geometry, and physics, in the October (1902) number of the Educational Review. In the Lewis Institute of Chicago, Professor P. B. Woodworth, of the Department of Electrical Engineering, has organized courses in engineering principles and electrical engineering in which are developed the fundamentals of practical mathematics. The general question came up at the first meeting * (Chicago, November, 1902) of the Central Association of Physics Teachers, and it is to be expected that this association will enlarge its functions in such a way as to include teachers of mathematics and of all the sciences, and that the question will be considered in its various bearings by the enlarged association. At this meeting informal reports were made from the Bradley Polytechnic Institute of Peoria, the Armour Institute of Technology of Chicago, and the University of Chicago. The question is evoking much interest in the neighborhood of Chicago.

I might explain how I came to be attracted to this question of pedagogy of elementary mathematics. I wish, however, merely to express my gratitude to many mathematical and scientific friends, in particular, to my Chicago colleagues, Mr. A. C. Lunn and Professor C. R. Mann, for their coöperation with me in the consideration of these matters, and further to express the hope that we may secure the active cooperation of many colleagues in the domains of science and of administration, so that the first carefully chosen steps of a really important advance movement may be taken in the near future.

I close by repeating the questions which have been engaging our attention this afternoon. In the development of the individual in his relations to the world, there is no initial

\footnotetext{
* Subsequent to the meeting of organization in the spring of $1902 . \mathrm{Mr}$. Chas. H. Smith, of the Hyde I'ark High School, Chicago, is president of the Association. Reports of the meetings are given in School Scrence (Ravenswood, Chicago).
} 
separation of science into constituent parts, while there is ultimately a branching into the many distinct sciences. The troublesome problem of the closer relation of pure mathematics to its applications : can it not be solved by indirection, in that through the whole course of elementary mathematics, including the introduction to the calculus, there be recognized in the organization of the curriculum no distinction between the various branches of pure mathematics and likewise no distinction between pure mathematics and its principal applications? Further, from the standpoint of pure mathematics : will not the twentieth century find it possible to give to young students during their impressionable years in thoroughly concrete and captivating form the wonderful new notions of the seventeenth century? By way of suggestion these questions have been answered in the affirmative, on condition that there be established a thoroughgoing laboratory system of instruction in primary schools, secondary schools, and junior colleges - a laboratory system involving a synthesis and development of the best pedagogic methods at present in use in mathematics and the physical sciences.

\section{CONCERNING THE AXIOM OF INFINITY AND MATHEMATICAL INDUCTION.}

BY PROFESSOR C. J. KEYSER.

(Read before the American Mathematical Society, December 29, 1902.)

\section{Introductory Considerations.}

This paper deals with a question which, on the one hand, is a question of pure logic, and, on the other, a question of Mengenlehre. It is often asserted, and is probably true, that reasoning naturally takes place in accordance with what the logicians of the school called first intentions. But ratiocination as activity, however unconscious its conformation to law, is nevertheless not lawless; and from the period when this fact came clearly into the consciousness of the Greek mind, as early as the time of Protagoras,* science has been neither able nor

* The so-called laws of thought seem to have struggled into consciousness mainly through the disputations of the Sophists. The law of contradiction, in particular, appears to have received its earliest formulation in the $\kappa a \tau a \beta a ́ \lambda \lambda \nu \varepsilon \varepsilon$ of Protagoras. Cf. Windelband: Geschichte der Philosophie, and Ueberweg : System der Logik (both works also in English). 